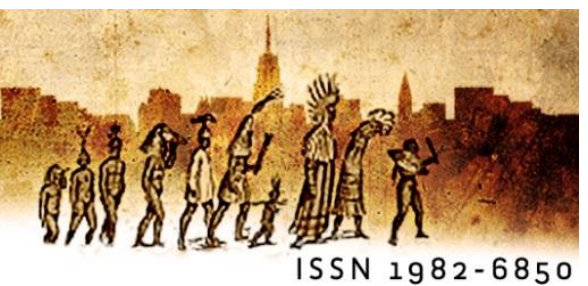

\title{
Máquinas que trituram indiferença - o teatro de Samuel Beckett
}

\author{
Cláudia Maria de Vasconcellosi, USP
}

Resumo: O ensaio analisa duas estratégias do teatro de Beckett para desestabilizar hábitos estéticos do público e do próprio gênero artístico. A primeira, uma estratégia de estranhamento ao cânone, e portanto metateatral; a segunda, uma estratégia de imersão do público na obra, contra o hábito contemporâneo do distanciamento.

Palavras-chave: Beckett, hábito, distanciamento, efeito de imersão, público

Abstract: This essay analises two strategies found in Beckett's theatre to destabilize audience's aethetic habits and the very core of the dramatic genre. The former is a strategie of estrangement related to the canon, and thus metatheatrical; the second is a strategy of immertion, notably immertion of the audience in the work, to counteract the contemporary habit of estrangement.

Key-words: Beckett, habit, estrangement effect, immertion effect, audience

\section{INTRODUÇÃO}

O ar está cheio de nossos gritos [...]. Mas o hábito é uma grande surdina.

Esperando Godot, Samuel Beckett

As peças de Samuel Beckett podem ser chamadas de máquinas que trituram indiferença, se levarmos em conta duas estratégias encontradas em seus escritos e devotadas a afastar o público primeiramente de seu conforto dramático, e em um segundo momento, de seu conforto crítico.

Em um primeiro momento, as máquinas que trituram indiferença visam o hábito dramático, entendido como a força irracional e resiliente, que vigora tanto na construção dos 
dramas, fato que concerne ao autor; como na espectativa dramática, fato que concerne ao público.

Em um segundo momento, as máquinas que trituram indiferença visarão o hábito Metateatral, surgido após a empreitada antidramática. As peças buscarão desestabilizar o platô em que a crítica se alojou para julgar a obra beckettiana com distanciamento e perspicácia.

A definição de hábito encontrada no ensaio de Beckett sobre Proust - "o hábito é o lastro que acorrenta o cão a seu dono" (BECKETT, 2013, p.17) -, explicita a qualidade de sua estima por esta força irresistível.

No mesmo ensaio, Beckett pôde ainda iluminar o poder adaptativo do hábito, remomorando a passagem em que o menino Marcel, sofre por estranhar sua primeira estada em Balbec-Plage. Ele fica horrorizado pela novidade da mobília, das explosões do relógio, das cortinas roxas, pela separação de seus pais, mas o horror maior é saber que logo a dor da separação será sucedida pela indiferença e a alquimia do hábito terá feito de um ser que sofre, alguém simplesmente insensível àquilo tudo (BECKETT, 2013, pp.23-5).

\section{PRIMEIRA PARTE}

A maior parte da obra teatral de Samuel Beckett pode ser chamada de Metateatral ${ }^{1}$. Ela tem como escopo desestabilizar as bases resistentes do drama clássico, tematizando-as nos enredos. Daí o efeito de estranhamento alcançado pelo autor, e muitas vezes confundido com o absurdo meditado pela filosofia existencial.

O público, por meio deste tipo teatro, é provocado a retirar-se de seu conforto dramático, ou seja, é provocado a estranhar sua centenária domesticação aos padrões do teatro aristotélico.

\footnotetext{
${ }^{1}$ Para um estudo detalhado das cinco primeiras peças teatrais de Samuel Beckett sob a ótica Metateatral ver: Vasconcellos, Cláudia Maria de; Teatro Inferno: Samuel Beckett, São Paulo: Terracota, 2012.
} 
É pelo poder do hábito que persistem até hoje e com a força da verdade todos aqueles truques de que os dramaturgos dispõem para criar a ilusão de verossimilhança. De que truques se trata? Por exemplo, do conflito dialógico - motor da história; da continuidade, sequência e causalidade - forjadoras de lógica; da presença no presente; e de começo, meio e fim, dipostos nesta ordem.

Cada um destes truques dramáticos são cuidadosa e exaustivamente denunciados por Beckett em sua obra. Seguem alguns exemplos de como isso se dá:

- O teatro de Beckett não se estrutura mais sobre o diálogo, não se detecta nele nem mesmo a conversação ibiseniana. O que se apresenta é uma conversa sem alvo, sem futuro, nem passado: "enquanto esperamos, vamos tratar de conversar com calma, já que calados não conseguimos ficar" (BECKETT, 2005, p. 120), diz Estragon em Esperando Godot (1952).

- O conflito, motor do drama tradicional, não é possível em Bekcett por conta da diferença de poder entre os personagens, o que simplesmente obriga uns a acatarem a decisão dos outros. Em Fim de Partida (1957) pode-se ouvir estas palavras:

Hamm: Não vou dar mais nada para você comer.

Clov: Então nós vamos morrer.

Hamm: Vou dar apenas o suficiente para você não morrer. [...]

Clov: Então não vamos morrer! (BECKETT, 2002, p.43)

- Como consequência da falta de conflito segue-se a falta de ação. Pessoas jazem num lugar e esperam, inventando histórias e memórias.

- O presente dramático é substituído pelo passado épico, como em A Última Gravação de Krapp (1958); além disso, a própria presença do personagem é substituída - ou pelo menos mitigada - por vozes acusmáticas.

- A continuidade e a lógica tornam-se impossíveis, quando os personagens sofrem de perda de memória: "Não me lembro de ter encontrado ninguém ontem. Mas amanhã 
não vou me lembrar de ter encontrado ninguém hoje. Não conte comigo para esclarecer nada" (BECKETT, 2005, p. 181), diz o então cego Pozzo a Vladimir. E o trio da peça Comédia (1963), encerrado em urnas funerárias, não pode se lembrar do momento em que trocou uma vida agitada e colorida para um estático e funesto aprisionamento.

- Não há mais finais nas peças de Beckett, porque peças são manifestações virtualmente sem fim, sujeitas a reencenação. Isso explicaria a afirmação de Winnie, em Dias Felizes (1961), sobre sua sombrinha recém carbonizada: "Acho que isso já deve ter acontecido antes, mesmo que não me lembre" (BECKETT, 2010, P.46).

- Não há começo quando a cortina se abre, porque algumas peças iniciam quando todas as razões e motivações para prosseguir desapareceram. Como Clov diz no começo de Fim de Partida: "Acabou, está quse acabado, quase acabando, deve estar quase acabando" (BECKETT, 2002, p.38).

- Beckett visa inclusive a expressividade da obra de arte: "Não estamos começando a... a... significar alguma coisa?" (BECKETT, 202, p.81), pergunta Hamm para Clov. O autor diligentemente impede que o público saia do teatro com alguma mensagem, ou conclusão, com algum juízo de valor.

Se é para estranharmos todas os componentes do jogo dramático, o público como elemento essencial não poderia ficar de fora. De fato, pouco a pouco, a medida em que sucedem as obras, nota-se a platéia sendo puxada, cada vez mais escancaradamente, para cima do palco e para dentro do enredo. As máquinas que trituram indiferença têm a habilidade de nos abduzir.

Quando Vladimir, ao final do segundo ato, observando Estragon dormir declara que "também para mim algúem está olhando, também sobre mim alguém estará dizendo: ele está dormindo, ele não sabe nada, deixe-o dormir" (BECKETT, 1976, p. 178), o que faz é incluir sutilmente a platéia na história. 
Do mesmo modo, quando Winnie acorda no segundo ato de Dias Felizes e louva a luz e os olhos que ainda olham para os seus olhos, que ainda se preocupam com ela (BECKETT, 2010, p.55), fica implícita uma delicada quebra da convenção teatral da quarta parede. Winnie, portanto, também introduz o público no enredo, revelando-o para si mesmo.

O papel do público no jogo dramático, no entanto, não é nem um pouco lisonjeiro. A platéia é retratada como uma espécie de voyeur, velada no escuro, e alferindo prazer em observar um ser que sofre enquanto despe seus segredos sobre o palco. Pior ainda, o público é retratado como uma espécie de torturador, inflingindo nos personagens a obrigação de atuar e de falar, a despeito de sua exaustão e de seu desejo de parar. O público tortura os personagens simplesmente pelo fato de estar ali, no teatro.

A peça Comédia encena a atividade de um refletor, que investiga as aventuras e desventuras de três personagens envolvidos em um triângulo amoroso. A conexão entre o inquisidor mecânico - o refletor - e a platéia (um representando a outra) é evidente. Esta pode se reconhecer nas palavras com que o personagem homem acusa seu inquisidor: "Mas agora, que você é apenas... um olho. Sem piscar. A olhar para o meu rosto [...] Um simples olho. Sem mente. [...] Estarei pelo menos... sendo visto?" (BECKETT, 1986, p. 317)2. Um olho sem mente, eis a definição da platéia acomodada pelo hábito dramático.

Esperando Godot, Fim de Partida, Dias Felizes, Comédia, assim como Eu Não, são peças que, com a quebra da quarta parede, conseguem sequestrar a platéia para dentro da trama. É deste novo e incômodo posto, é neste espelho, que podemos nos observar, e nos compreender como vouyeurs e torturadores, como elementos dramáticos obsoletos, que o hábito tornou resistentes.

SEGUNDA PARTE

${ }^{2}$ Minha tradução. 
Demover o público do conforto dramático, contudo, não garante que ele não venha a encontrar uma nova forma de estabilidade e segurança, não impede que ele passe a se sentir a vontade com o Metateatro e assim como o menino Marcel transforme o estranhamento inicial, em um estado de indiferença.

Para evitar, portanto, as artimanhas adaptativas do hábito, Beckett cria uma segunda estratégia que desestabilizará o público do conforto pós-dramático, ou Metateatral.

Improviso de Ohio (1981) ilustra este procedimento. Trata-se de um texto planejado como armadilha para um público específico, um público formado por especialistas. A peça foi encomendada pelo Professor Gontarski, para um simpósio internacional promovido pela Ohio Universtiy, em homenagem aos 75 anos de Samuel Beckett (KNOWLSON, 1996, p.664).

O texto, leva em consideração este fato, e lança muitas iscas para um público inteligente, crítico e preparado.

Tanto é, que na noite de estréia, quando a cortina foi aberta, a austeridade da cena não impediu que a platéia risse, reconhecendo imediatamente a provocação do autor. $\mathrm{Na}$ cena, dois velhos, um lendo e outro ouvindo, duplicavam o cotidiano de estudos da platéia de professores. Além disso, a peça se movia no já establizado terreno Metateatral. Afinal, ouvir e ver/ler, são as tarefas cruciais de qualquer platéia.

Não bastasse isso, à medida que o espetáculo progredia, Beckett oferecia ao público a satisfação de inúmeros doutos reconhecimentos:

- o chapéu joyceano sobre a mesa;

- a referência à Ilha dos Cisnes, por onde Beckett e Joyce costumavam passear;

- a palavra Ohio, do título, que não faz referência apenas à Univserdiade que albergava o simpósio, mas a um rio mencionado no Finnegans Wake; 
- o trocadilho entre white nights, noites brancas, significando insônia, e Whiteknights (com K), cavaleiros brancos, indicando o local na Universidade de Reading onde se encontravam à época os arquivos do autor;

- e o trocadilho entre reading (ler) e Reading (a universidade).

No entanto, enquanto distraía a platéia no parque dos reconhecimentos, a máquina Ohio a direcionava concomitantemente para um lugar onde nem a erudição, nem um extenso conhecimento sobre o drama serviriam.

A cena, o quadro estático, que o público contempla por 20 minutos - um homem lendo em voz alta e o outro ouvindo - está posta em abismo na estrutura da peça. O que se vê no palco espelha uma imagem da história lida.

Assim, a cena, contrariando o que é normalmente convencionado, apresenta ficcionalidade maior do que a história narrada; pois a cena está alojada na profundeza do livro, e parece ser uma emanação da narrativa.

Ora, se concordarmos que palco e platéia dividem o mesmo espaço físico, poderemos aceitar que ambos terão, por contaminação poética, um mesmo grau de realidade. Pouco a pouco, o público é direcionado não para cima do palco, mas para dentro do livro, para essa distância que Beckett em Improviso de Ohio chama de profundezas da mente ou abismos de consciência.

A estrutra da peça permite um deslocamente curioso do público para o reino da fábula, onde alguém perdeu um ente querido, onde uma triste história é contada, onde um ser solitário precisa de conforto e companhia.

Esta segunda estratégia usada por Beckett para desestabilizar um novo hábito, o hábito Metateatral, eu chamo de efeito de imersão (por contraste ao efeito de distanciamento). Não se trata de um procedimento ilusionista, mas de um método que se vale do público, para reconfigurar os pseudo-casais encontrados em tantas de suas obras. 
Mercier e Camier, Didi e Gogo, Pozzo e Lucky, Winnie e Willie, Hamm e Clov, são exemplos dos pseudo-casais referidos no romance O Inominável (WELLER, 2010, pp.127-8), exemplos que concretizam o oxímoro "sozinhos juntos" (imagem forte de Improviso de Ohio). Quando, no entanto, o estar sozinho junto com um outro personagem se torna impossível ou insuficiente, há ainda a possibilidade de dividir-se a si mesmo, para fazer-se companhia. Hamm explica esta técnica: "Depois falar, depressa, como a criança sozinha que se divide em muitas, duas, três, para ter companhia, conversar com outros, no escuro" (BECKETT, 2002, p.129). E se a divisão de si mesmo, parecer também insatisfatória, existe uma nova possibilidade, a de valer-se do público, de levá-lo para uma outra posição, tirá-lo do cruel posto de voyeur, e encaminhá-lo para a posição de companhia³.

Nacht und Träume (1982), peça televisiva, encena um outro modo do efeito de imersão, posicionando a platéia num lugar surpreendente.

Esta peça conta com dois personagens, o sonhador, e uma figura velada, que aparece apenas no sonho daquele, e de quem só as mãos são reveladas.

O sonho duplica a posição do sonhador em uma sala escura - descansando as mãos sobre a mesa e a cabeça sobre as mãos -, mas duplica-a de modo espelhado.
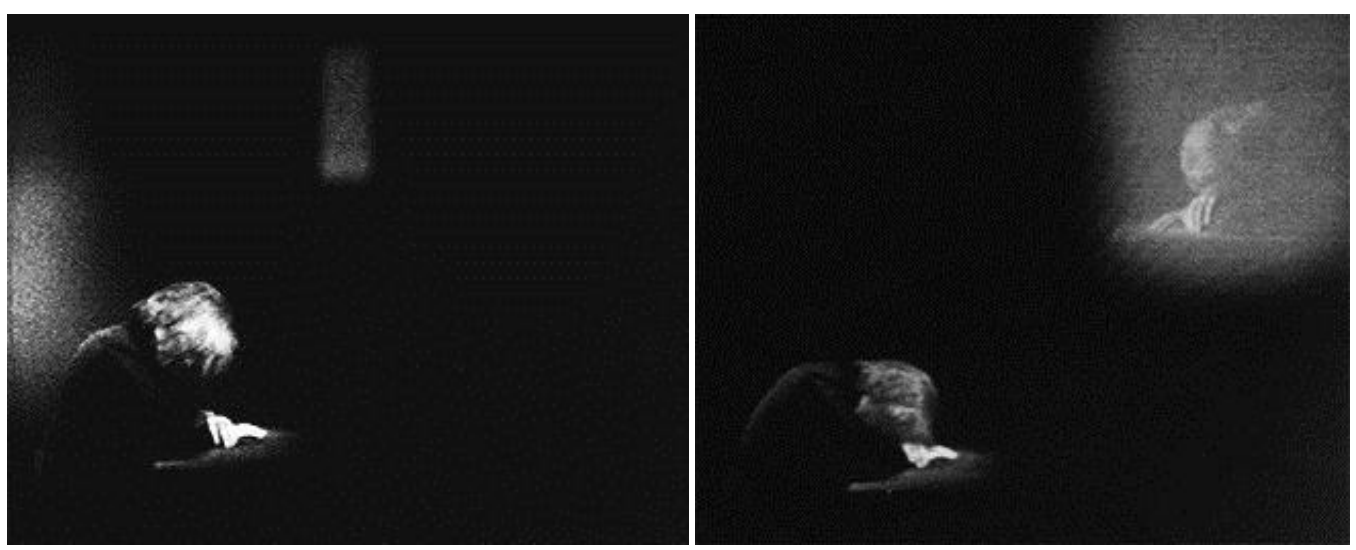

Nacht und Träume, peça para TV de Samuel Beckett, S.D.R, Stuttgart, 1983 (foto de H.Jehle)

\footnotetext{
3 Um estudo abrangente da peça Improviso de Ohio pode ser encontrado em meu livro: Vasconcellos, Cláudia Maria de; Samuel Beckett e seus Duplos - Espelhos, Abismos e outras Vertigens Literárias, São Paulo: lluminuras, 2017.
} 
No sonho, por trás do personagem, emergindo do escuro, duas mãos despontam. Primeiramente para o acordar gentilmente. Depois para oferecer-lhe um pouco de bebida em uma taça. Em seguida para secar sua testa com um pano, como se ele estivesse muito cansado. E assim que as mãos retornam para a sombra, o sonhador evoca-as mais uma vez levantando sua mão direita. As mãos, então retornam. A primeira o sonhador segura entre as suas, encaminhando-as suavemente para a mesa, onde novamente repousa a fronte; a segunda toca levemente os seus cabelos, num gesto de consolação.

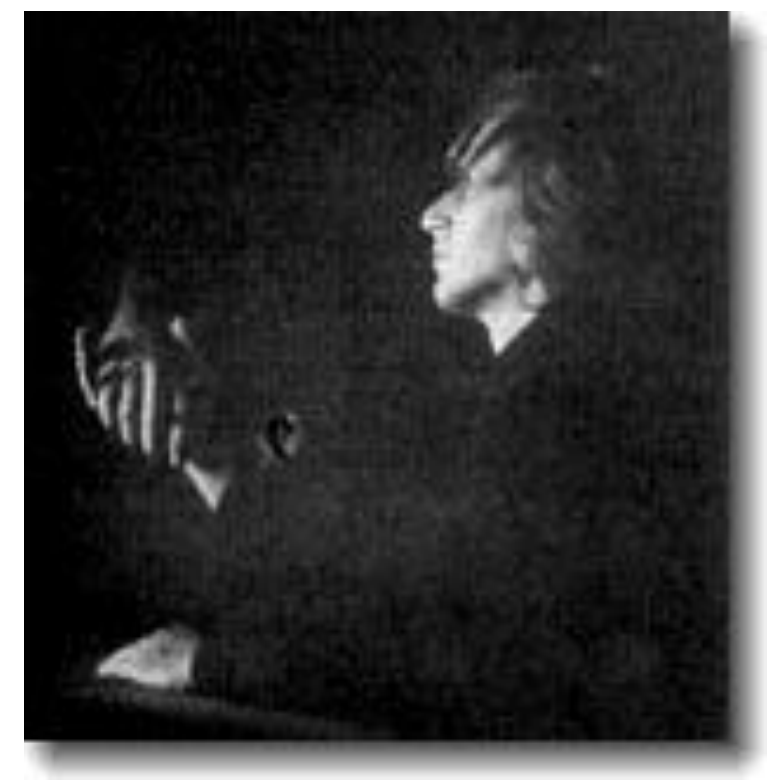

Nacht und Träume, peça para TV de Samuel Beckett, S.D.R, Stuttgart, 1983 (foto de H.Jehle)

A sequência "realidade solitária e sonho" repete-se duas vezes. Ao final, no entanto, o sonhador é revelado sozinho como no quadro inicial. Esta imagem esvanece até desaparecer, como se fosse nosso sonho.

Contudo, o papel da platéia em Nacht und Träume não é só de espectador. A máquina teatral beckettiana também a desloca para dentro da peça, e de modo abismal. Pois nós, enquanto espectadores, somos encaminhados diretamente para o sonho, estamos posicionados no mesmo lugar da entidade oculta. 
Note que, na frente da tela, estamos na frente da imagem do sonhador. Quando o sonho reproduz a mesma imagem, mas espelhada, nossa posição se desloca para trás do sonhador, para a mesma escuridão de onde as mãos despontam.

A máquina Nacht und Träume faz o público despontar na história, como a companhia ansiada pelo personagem.

Para encerrar, devo dizer que se o público pode sentir-se confortável após domesticar o estramento produzido pelo Metateatro, poderá do mesmo modo adaptar-se ao constrangimento de estar sozinho junto dentro do enredo no fundo da mente de um personagem.

De modo que, se as máquinas beckettianas não tivessem sua produção interrompida em 1989, acredito que contaríamos com mais tipos de desestabilizares de certezas. Ao que me parece, o teatro de Beckett alocaria constantemente o público para moradas estranhas, desconfortáveis e imprevisíveis, e aí o abandonaria, ao menos pelo tempo em que o hábito não tivesse ainda organizado o caos e amansado nosso desassossego.

\section{BIBLIOGRAFIA}

Beckett, Samuel; Dias Felizes, trad. Fábio de Souza Andrade, São Paulo: Cosac\&Naify, 2010.

; Esperando Godot, trad. Fábio de Souza Andrade, São Paulo: Cosac\&Naify, 2005.

; Esperando Godot, trad. Flávio Rangel, São Paulo: Abril Cultural, 1976,

; Fim de Partida, trad. Fábio de Souza Andrade, São Paulo:

Cosac\&Naify, 2002.

;Proust, São Paulo: Cosac\&Naify, 2003. 
Samuel Beckett - The Complete Dramatic Works, London: Faber and

Faber, 1990.

Knowlson, James; Damned to Fame - The Life of Samuel Beckett, London: Bloomsbury, 1996.

Terracota, 2012.

Weller, Shane; "Beckett and Ethics" in Gontarski, S.E. (editor); A Companion to Samuel Beckett, Singapure: Wiley-Blackwell, 2010.

i Cláudia Maria de Vasconcellos, doutora em Letras - USP, é escritora, atuando como ensaísta, dramaturga, roteirista e contista. Sua obra ficcional está voltada para o público adulto e infanto-juvenil. Autora de Samuel Beckett e seus Duplos - Espelhos, Abismos e outras Vertigens Literárias, São Paulo: Iluminuras, 2017; e Teatro Inferno: Samuel Beckett, São Paulo: Terracota, 2012. 